\title{
O USO DO OBJETO DE APRENDIZAGEM TUX PAINT NA PRODUÇÃO ESCRITA EM LÍNGUA PORTUGUESA COM ALUNOS SURDOS
}

\author{
Dilma Pereira dos Santos, Raquel Rosan Christino Gitahy \\ Universidade do Oeste Paulista - UNOESTE, Presidente Prudente, SP. E-mail: isadilma2@hotmail.com
}

\section{RESUMO}

O presente artigo refere-se a uma pesquisa que visou investigar a influência do objeto de aprendizagem Tux Paint como recurso pedagógico para promover o desenvolvimento da leitura e escrita de alunos surdos, através de uma linguagem visual atrativa a especificidade do alunado surdo. Os sujeitos da pesquisa foram três alunos surdos, entre 9 a 10 anos de idade; devidamente matriculados no ensino fundamental, que cursavam o quarto ano em uma escola que atendia a crianças surdas em Foz do Iguaçu, Paraná. A pesquisa utilizou a investigação qualitativa do tipo estudo de caso. Como procedimentos foram realizados: Uma observação estruturada diagnóstica, coletas dos documentos produção e interpretação de textos desenvolvidos pelos alunos, verificando a qualidade da produção e interpretação textual desses alunos. Em seguida, aplicou-se atividades de intervenção com o objeto educacional Tux Paint que visa à produção escrita e leitura. Uma segunda avaliação foi realizada para determinar se houve mudança quanto a produção da escrita e interpretação textual. Como resultado verificou-se a importância e validade pedagógica de tal objeto educacional

Palavras-chave: Tux Paint; educação; surdos; escrita; leitura

\section{THE LEARNING OBJECT OF USE TUX PAINT PRODUCTION IN WRITING PORTUGUESE STUDENTS WITH DEAF}

\begin{abstract}
This article refers to a study that aims to investigate the influence of Tux Paint learning object as an educational resource to promote the development of reading and writing of deaf students through an attractive visual language specificity of the students. The subjects were three deaf students between 9-10 years of age; properly enrolled in elementary school, who attend the fourth year in a school that serves deaf children in Foz do Iguaçu, Paraná. The research used a qualitative investigation of a case study. How procedures will be performed: A diagnostic structured observation, collection of document production and interpretation of texts developed by the students, checking the quality of production and textual interpretation of these students. Then intervention activities will be applied to the educational object Tux Paint aimed at producing writing and reading. A second evaluation will be conducted to determine if there was a change as the writing production and textual interpretation. As a result there is the importance and validity of such pedagogical educational object.
\end{abstract}

Keywords: Tux Paint; education; deaf; writing; reading 


\section{INTRODUÇÃO}

O trabalho aqui apresentado é um recorte de alguns resultados obtidos no desenvolvimento da pesquisa qualitativa desenvolvida ao longo do mestrado em educação. Neste trabalho tomou-se como foco o uso de objeto de Aprendizagem Tux Paint na produção textual. Ao longo da trajetória acadêmica surgiu o tema deste trabalho que nasceu na caminhada em busca de respostas aos questionamentos sobre o processo de produção o textual do aluno surdo. Ao desenvolver a pesquisa e a vivencia de sala de aula, corroborou em destacar a prática docente e as dificuldades frente à realidade de aprendizagem do discente surdo.

Refletir sobre a educação do surdo é fundamental no processo de aprendizagem, visto que durante muitos anos a educação dos surdos passou por diferentes abordagens.

Ao pensar sobre a temática do aprendizado da língua Portuguesa (L 2), questionou-se: Como o objeto de aprendizagem influencia na aprendizagem do aluno surdo?

Esta questão justificou-se pois buscar caminhos para uma educação de qualidade com uma metodologia diferenciada com alunos que apresentam diferenças linguísticas é essencial.

Para fundamentar o trabalho retomou-se a história da educação de alunos surdos e deparou-se com uma realidade modificada, através dos tempos. Essa realidade emergiu pelas lutas da comunidade surda com apoio dos pais e entidades que se preocupavam com a educação desses indivíduos. Desta forma foi que surgiram as escolas no Brasil voltadas aos alunos surdos.

Segundo Sacks (1988), a escola francesa foi a primeira instituição educacional a atender as necessidades dos alunos surdos no Brasil e com isto influenciou profundamente a educação dos surdos. Desta influência foi criado Instituto de Surdos-Mudos, conhecido hoje como INES -Instituto Nacional de Educação de Surdos. Essa instituição foi fundada em 26 de setembro de 1857 pelo professor surdo francês Ernet Hwet, que veio ao Brasil a convite do Imperador D. Pedro II para trabalhar na educação de surdos (SACKS, 1988).

Depois do período da monarquia, os surdos foram ganhando espaços à medida que novas leis surgiam como a constituição de 1988 e com a Declaração de Salamanca.

No texto da Constituição brasileira (1988) em seu artigo 208, fica garantido “O atendimento especializado aos portadores de deficiência, na rede regular de ensino". Deixa claro as diretrizes e bases da educação nacional procurando trazer a garantia de "atendimento educacional especializado aos portadores de deficiência, preferencialmente na rede regular de ensino", desta forma priorizando a inclusão social. 
Segundo constitucional no entendimento da lei, a "educação especial" é definida no artigo 58, como "a modalidade de educação escolar na rede regular de ensino, para educandos portadores de necessidades especiais." ( BRASIL, 1988)

A Declaração de Salamanca deixa claro sua posição quanto a educação de indivíduos com necessidades especiais.

(...) a expressão necessidades educacionais, especiais refere-se a todas as crianças e jovens cujas carências se relacionam a deficiências ou dificuldades escolares". (...). Neste conceito, terão que se incluir crianças com deficiências ou superdotados, crianças de rua ou crianças que trabalham crianças de populações remotas ou nômades, crianças de minorias lingüísticas, etnias ou culturais e crianças de áreas ou grupos desfavoráveis ou marginais. (DECLARAÇÃO DE SALAMANCA, 1994, p. 15)

Há um determinado consenso que é necessário haver uma base de aprendizagem sólida, a fim de que os alunos surdos adquiram a competência da leitura e escrita. Contudo, como podemos desenvolver a leitura e escrita em alunos com comprometimento auditivo?

A habilidade de leitura segundo Marchesi e Martin (1995, p.204) requer vocabulário: "a compreensão de texto está vinculada à amplitude do vocabulário, o conhecimento das estruturas sintáticas e o conhecimento que se refere tanto à estrutura da narração como a sua experiência pessoal." Logo para que a leitura se desenvolva é necessário que haja conhecimentos prévios dos elementos que constituem um texto, desta forma propiciar a interação social e diferentes formas de comunicação é fundamental nesse processo.

Assim se expressa Sacks (1998, p. 44):

As crianças surdas precisam ser postas em contato primeiro com pessoas fluentes na língua de sinais, sejam seus pais, professores ou outros.

Assim que a comunicação por sinais for aprendida - e ela pode ser fluente aos três anos de idade, tudo então pode decorrer: livre intercurso de pensamento, livre fluxo de informações, aprendizado da leitura e escrita.

Os alunos surdos, dependendo do nível de escolarização em que se encontram, possuem um domínio maior ou menor da língua de sinais e esta é utilizada na interação social na comunidade surda e com ouvintes que tenham domínio da linguagem. Sendo assim, o nível de leitura e escrita está atrelado ao nível de conhecimento de Libras.

Segundo Mendes e Novaes (2003), o modelo de aprendizagem interativo possibilitaria o aluno a utilizar diferentes instrumentos permitindo seu crescimento cognitivo, social e afetivo, através de histórias contadas, libras e oralmente proporcionando o leitor lê e buscar compreender o texto em uma totalidade. "o conhecimento prévio e sua interação no processo de leitura e 
compreensão dos textos são enfatizados, destacando, os detalhes dos textos para construir o significado" (MENDES; NOVAES, 2003, p.129).

Partindo das bases teóricas é importante destacar o professor como mediador do processo de ensino e aprendizagem (VYGOTSKY, 2000). As metodologias e estratégias aplicadas pelo professor são fundamentais no processo de leitura, pois é por meio das estratégias e formulação de uma linguagem própria, a do aluno surdo, que o desenvolvimento linguístico ocorre e permite a compreensão da linguagem de forma clara. Neste sentido, apresentar a linguagem de forma interativa e divertida, através da tecnologia de informação e comunicação pode possibilitar uma prática pedagógica eficaz.

Para Silva (2008), a tecnologia é um instrumento que possibilita oportunidades de aprendizagem e interação no ambiente escolar. Como diz Silva (2008, p.40):

[...] acredito nas relações, nos vínculos que se estabelecem nas relações humanas que acontecem dentro dos muros escolares [...] numa escola compatível com a sociedade contemporânea, uma escola mais justa, mais democrática, menos preconceituosa, e, também, mais equiparada tecnologicamente.

Com o objetivo da educação de qualidade e o uso da TIC na educação dos surdos destacamos os objetos educacionais de aprendizagem.

Segundo Sá Filho, Soares e Machado (2003), um objeto de aprendizagem (OA) se constitui em todo instrumento digital utilizado para promover a aprendizagem do educando. Sendo assim, o professor deve desenvolver habilidades que permitam o uso dessas ferramentas em sua práxis.

O professor deve estar atento às potencialidades e limitações dos softwares escolhidos. Particularmente, prefiro que o professor pense em termos de uso educacional de software e no uso do software educacional. Porque acredito que qualquer software tem potencial educativo, desde que esteja a serviço de um projeto de aprendizagem.

Assim um software é adequado ou não, desde que contextualizado, ou seja, é preciso responder as questões: por que, para quem e como um determinado software poderá ser utilizado. Quando um professor tem clareza de seus objetivos, preocupa-se em envolver o aluno na ludicidade da proposta, como na análise de conceitos implícitos nas situações apresentadas, contextualizando-as ao mundo em que o aluno vive. Desta forma provoca reflexões que ajudam o aluno a identificar-se em seu espaço-tempo sociocultural (MARTINS, 2004, p.5).

Desta forma, garantir um ensino inovador que possibilite ao discente desenvolver suas habilidades e competências, torna-se relevante a pesquisa uma vez que busca avaliar o processo de aprendizagem da língua portuguesa com alunos surdos tendo como instrumento mediador os 
objetos de aprendizagem educacionais. Assim, o objetivo geral da presente pesquisa foi avaliar a influência do objeto de aprendizagem Tux Paint no desenvolvimento da leitura e escrita da Língua Portuguesa com alunos surdos.

\section{METODOLOGIA}

A presente pesquisa foi cadastrada na plataforma Brasil para analise do comitê de ética, tendo sido aprovada e recebendo o número CAAE 32059814.1.0000.5515

O trabalho de pesquisa foi estudo de caso em uma análise qualitativa.

O contexto do projeto apresentado foi realizado em uma unidade escolar de ensino fundamental com toda uma turma de quarta série composta por três alunos entre 9 a 10 anos de idade, no município de Foz do Iguaçu Paraná, em uma escola que atende a crianças surdas desde o Pré- escolar até o quinto ano.

Em todo o processo da pesquisa foi utilizado linguagem de sinais em contexto do ambiente escolar, desta forma não houve obstáculo quanto à comunicação entre pesquisador e o sujeito da pesquisa.

Esta unidade escolar possui um laboratório de informática e em seu Projeto Político Pedagógico e constava a utilização dos computadores do laboratório de informática como recursos educacionais complementares as atividades pedagógicas realizadas em sala de aula. Porém, atualmente encontra-se desativado devido à falta de projetos que visem o uso educacional desse laboratório.

Durante o processo de intervenção, fez-se a observação estruturada e a analise documental dos textos produzidos com o processo de intervenção utilizando o objeto de aprendizagem Tux Paint.

O Tux Paint tem uma interface simples e acessível apresenta, uma tela em branco, com várias ferramentas, podendo ser utilizada, pedagogicamente na produção de convites, desenhos, pequenos textos e frases. 


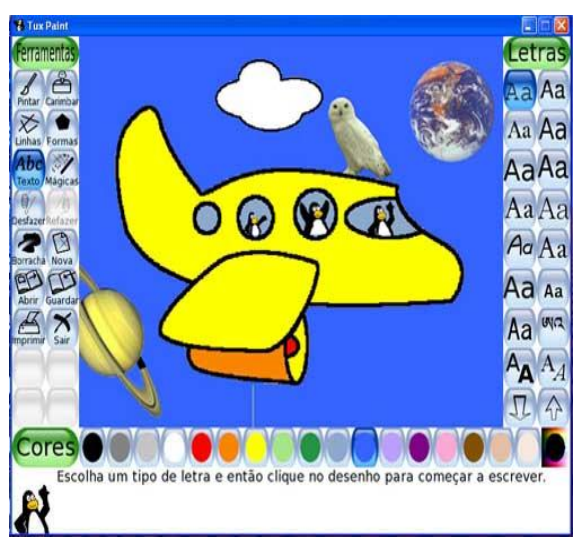

FIGURA 1.Tux Paint

Fonte: http://tux-paint.softonic.com.br/

Durante 2 dias foi ensinado ao aluno surdo o manuseio do software e em seguida aplicado atividades pedagógicas

A primeira atividade os alunos selecionaram 2 desenhos de animais e em seguida produziram frases referente a esses animais e fizeram a leitura em libras dessas frases.

A segunda atividade foi relacionada à produção frases. O aluno deveria selecionar 2 desenhos de objetos na produção de frases e em seguida fazer a leitura em libras

Na produção das frases primeiramente o aluno era estimulado a formular e dar exemplo em libras. Em seguida as frases eram escritas na lousa com a estrutura em libras em seguida foi realizada a estruturação das frases apresentando aos alunos a estrutura da língua portuguesa. A lousa foi apagada e em seguida as atividades foram realizadas com o uso do software.

\section{RESULTADOS}

O aluno " $A$ " fez a frase em libras e depois a datilologia das palavras. Observou-se certa dificuldade na datilologia das palavras. Na palavra avião o aluno fez A V I teve dificuldade no ÃO. Na palavra VOA e LONGE não conseguiu realizar a datilologia.. No processo de registro da palavra através do teclado o aluno registrou perfeitamente a palavra que realizou a datilologia ( AVI) nas demais teve dificuldade.

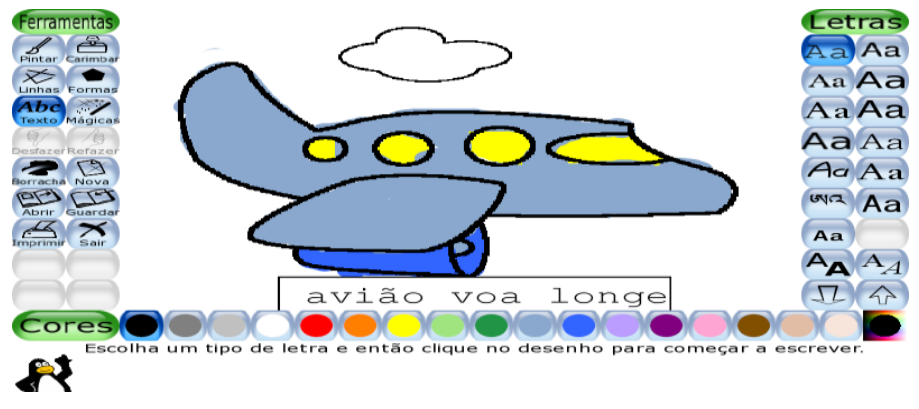

Figura 2. Produção do aluno "A" 
Nesta frase a aluna "B" sinalizou em libras a frase e na datilologia registrou a palavra RATO as demais palavras não conseguiu realizar a datilologia. Logo na hora de registrar utilizando o teclado registrou perfeitamente a palavra RATO nas demais palavras realizou com a intervenção do professor através da datilologia. O discente reconhece as consoantes e vogais em libras.

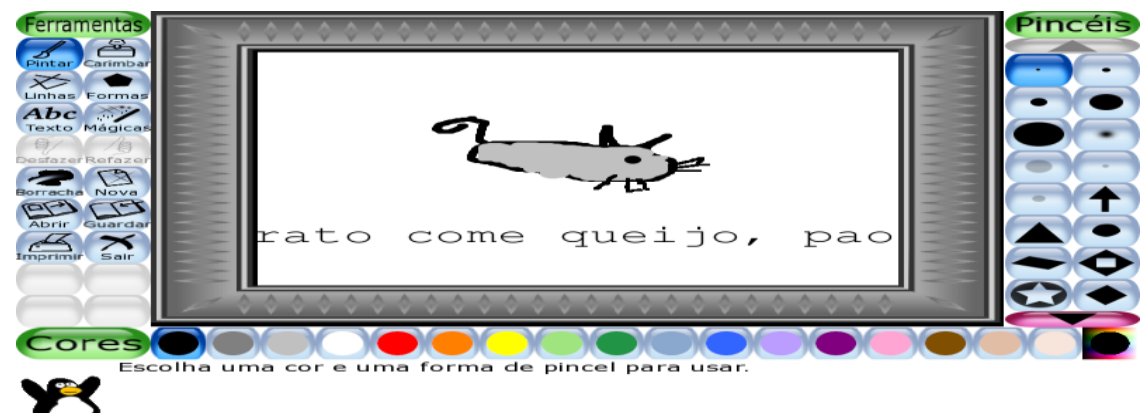

Figura 3. Produção da aluna "B"

Nesta frase a aluna "C" sinalizou em libras " O CACHORRO E O GATO SÃO AMIGOS" foi feito um questionamento perguntando para aluna porque o cachorro e o gato eram amigos. A aluna então completou a frase " porque eles brincam juntos" Percebe-se que quando estimulados a um questionamento como por que? Onde? O que? Os alunos ampliam o pensamento e a produção escrita de uma frase. A discente realizou em libras a frase e em seguida a datilologia de cada palavra. Foi bem sucedida na datilologia das palavras GATO, nas demais palavras teve dificuldades. Escreveu a frase com ajuda.

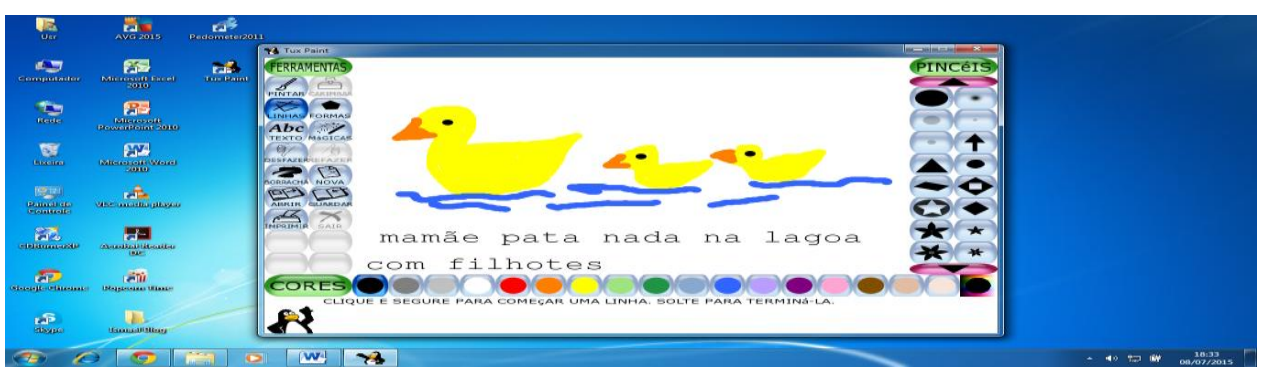

Figura 4. Produção da aluna " $C$ "

O processo de intervenção com o uso do Tux Paint ao fazer enfrentamento da produção escrita foi capaz de fomular ideias com lógica e coerência, embora lhe faltasse o conhecimento da escrita, o aluno se relacionou bem com o objeto de aprendizagem mostrando interesse e motivação na realização das tarefas. 


\section{DISCUSSÃO}

Na produção textual assumimos especial importância a forma como o docente conduzirá a mediação ao intervir na aprendizagem dos discentes com deficiência. Para facilitar a aprendizagem é necessário atribuir importância, significado, sentido, compreensão do texto que foi produzido, mesmo que sua produção seja distante do ideal. (GUARRINELLO, 2007).

Observando os textos produzidos verifica-se a grande dificuldade que os alunos tem na produção textual. Um dos critérios estabelecidos foi o uso adequado da pontuação. Neste sentido, o texto apresenta o esforço do aluno em pontuar, utilizando a vírgula e o ponto final. Outro elemento da estrutura da escrita foi a tentativa de parágrafo com frases curtas e diretas, além do uso da letra maiúscula no início das frases. O traçado as palavras são legíveis, porém não conseguiu escrever corretamente as palavras complexas. Com relação a coesão e coerência o texto apresenta-se quase que incompreensível. Porém observa-se que os alunos surdos tem criatividade e compreendem o tema que está sendo abordado na produção textual. Quando aplicado o objeto de aprendizagem os alunos tiveram uma reação mais motivadora, com expectativa. Verificou-se que o uso do Tux Paint, propiciou maior interesse na produção escrita, além disso observou-se que o uso do teclado ajuda na escrita, uma vez que o aluno não necessita fazer o traçado das letras.

\section{CONCLUSÃO}

As evidencias apontadas pelos resultados permitem concluir a importância do uso dos objetos de aprendizagem em sala de aula e a necessidade de propiciar novos instrumentos que venham a facilitar o desenvolvimento da leitura e escrita de alunos surdos diante de suas dificuldades e especificidades.

\section{REFERENCIAS}

BRASIL Congresso Nacional. Constituição da República Federativa, 1988.

DECLARAÇÃO DE SALAMANCA: Sobre Princípios, Políticas e Práticas na Área das Necessidades Educativas Especiais, 1994, Salamanca-Espanha.

GÓES, M.C. Linguagem, surdez e educação. Campinas/SP: Autores Associados, 1998.

GUARRINELlO, A. C. “O Papel do outro na Escrita do sujeito surdo”. São Paulo, Plexus,2007.

MARCHESI, A . E MARTIN, E. Da terminologia do distúrbio às Necessidades educacionais especiais. In: COLL, C. PALÀCIUS, J. E. MARCHESI, A . (org.) Desenvolvimento psicológico e educação: necessidades educativas especiais e a aprendizagem escolar. Porto Alegre: Artes Médicas, 1995. 
MENDES, B. C. A. e NOVAES, B. C. A. C. Oficina de Leitura com Adolescentes Surdos: Uma Proposta Fonoaudiológica. In. Linguagem Escrita - Referenciais para a Clínica Fonoaudiológica (Org.) Berberian, A . P. ; Massi, G. A . e Guarinello, A . C. - São Paulo: Plexus Editora, 2003.

SÁ FILHO, Clovis Soares e; MACHADO, Elian de Castro. O computador como agente transformador da educação e o papel do objeto de aprendizagem. Disponível em: htpp//www.abed.org.br/seminário 2003. Acesso 10 de Mai de 2015

SACKS, O. Vendo vozes: Uma jornada pelo mundo dos surdos. Rio de Janeiro: Imago, 1998.

SILVA, A. C. A representação social da surdez: entre o mundo acadêmico e o cotidiano escolar. In: FERNANDES, Eulália (org.). Surdez e bilinguismo. 2 Ed. Porto Alegre: Mediação, 2008. p. 39-50.

VYGOTSKY, L. S. A Formação social da mente. São Paulo: Martins Fontes, 2000. 